\title{
Erratum to: Separation of nanocarbons by molecular recognition
}

\author{
Naoki Komatsu
}

Published online: 29 June 2010

(C) Springer Science+Business Media B.V. 2010

\section{Erratum to: J Incl Phenom Macrocycl Chem DOI 10.1007/s10847-008-9418-4}

Unfortunately, the structures of figures 6 and 7 are not matched. There is also a small mistake in the caption of figure 7. Please find the corrected figure 7 and its caption below.

Furthermore, all mention of " $\mathrm{A} L$ and $\mathrm{A} R$ ", "armchair lines", and "A lines" in the section Optical resolution of single-walled carbon nanotubes by chiral diporphyrin nanotweezers should be replaced by " $Z L$ and $Z R$ ", "zigzag lines", and "Z lines", respectively. a

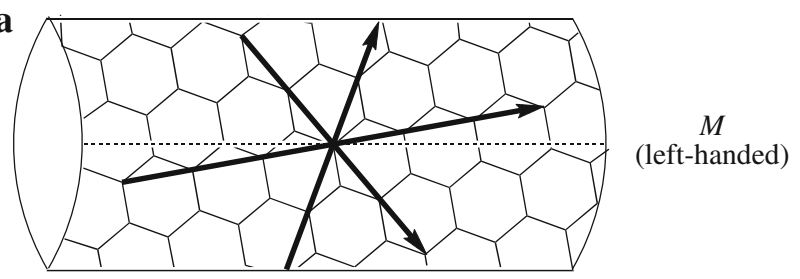

b

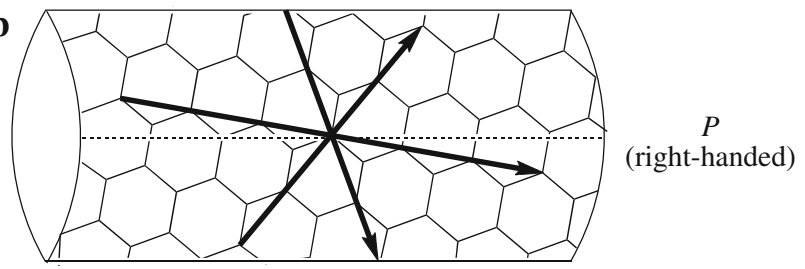

Fig. 7 Definition of $M$ (left-handed) and $P$ (right-handed) of SWNTs. Three arrows and dashed line indicate zigzag lines ( $\mathrm{Z}$ lines) and SWNT axis, respectively 